\title{
La protección jurídica de los conocimientos tradicionales de los pueblos indígenas en la comunidad andina
}

\author{
Esther Anaya Vera \\ Investigadora independiente \\ anaya.ea@pucp.pe
}

\begin{abstract}
RESUMEN
La Comunidad Andina (CAN), organización internacional de carácter supranacional centrada en las personas y regulada por el Derecho Comunitario, institucionaliza hace casi 50 ańos el proceso de integración andino-amazónico iniciado hace más de 5000 con la Civilización Caral y ocupa el territorio de sus Países Miembros: Bolivia, Colombia, Ecuador y Perú. Territorio comunitario en el cual habitan más de 200 pueblos indígenas cuyos conocimientos tradicionales son reconocidos por la CAN como parte del desarrollo de conocimientos en ciencia y tecnología, razón por la cual su protección está incorporada en el Régimen Común sobre Propiedad Industrial, entre otras normas supranacionales afines. En este contexto, el objetivo del presente artículo es identificar al enfoque de derechos humanos como el adecuado para proteger los conocimientos tradicionales de los pueblos indígenas, al ser estos la expresión de su identidad cultural, derecho fundamental de este colectivo protegido por el Derecho Internacional de los Derechos Humanos. Lo propuesto, a partir del análisis de la jurisprudencia del Tribunal de Justicia de la CAN.
\end{abstract}

Palabras clave: Tribunal de Justicia de la Comunidad Andina, Derecho Comunitario, pueblos indígenas, protección de los conocimientos tradicionales, identidad cultural, Derecho Internacional de los Derechos Humanos.

\section{The legal protection of the traditional knowledge of indigenous peoples in the andean community}

\begin{abstract}
The Andean Community (CAN by its abbreviation in Spanish), an international organization of supranational character is centered on people and regulated by Community Law. It was institutionalized almost 50 years ago. The process of Andean-Amazonian integration initiated more than 5000 years ago with Caral Civilization and occupies the territory of its Member Countries: Bolivia, Colombia, Ecuador and Peru. The Community territory in which more than 200 indigenous people live, whose traditional know-how is recognized by the CAN as part of the development of knowledge in science and technology, which is why its protection is incorporated in the Common Regime on Industrial Property, among other related supranational norms. In this context, the objective of this article is to identify the human rights approach as adequate to protect the traditional knowledge of indigenous people, as these are an expression of their cultural identity, the fundamental right of this group protected by the International Law of human rights. The proposal is from the analysis of the case law of the Court of Justice of the CAN.
\end{abstract}

KeYwords: Court of Justice of the Andean Community, Community Law, indigenous peoples, protection of traditional knowledge, cultural identity, International Human Rights Law. 
Evidencias arqueológicas encontradas en Caral, la segunda civilización más antigua del mundo, después de Mesopotania y anterior a Egipto, demuestran que hace más de 5,000 años se inició el proceso de integración cultural en la subregión andino-amazónica del planeta, el cual ha permitido que sus pueblos indígenas constituyan un patrimonio biológico y cultural común.

Esto también explicaría el porqué actualmente países andino-amazónicos como Bolivia, Colombia, Ecuador y Perú comparten similar biodiversidad, algunas de cuyas semillas con más de 5,000 ańos de antigüedad, son expuestas en los museos de sitio de Caral, en el departamento de Lima-Perú.

Es así como los alimentos nativos andino-amazónicos han sido domesticados y cultivados durante siglos por los pueblos indígenas que habitan los referidos países andino-amazónicos, los cuales hace casi 50 años decidieron dotar de un marco jurídico supranacional a su integración milenaria, con la creación de la Comunidad Andina (CAN), organización internacional de carácter supranacional centrado en las personas.

En los referidos países, reconocidos por sus propias constituciones políticas como multiétnicos y pluriculturales, coexisten numerosos pueblos indígenas, quienes con sus conocimientos tradicionales han logrado constituir un valioso patrimonio biológico, genético y cultural común a los cuatro Países Miembros de la CAN. En este sentido, su titularidad no es posible restringirla a ninguno de estos países ${ }^{1}$.

Por consiguiente, «en lugar de generar luchas entre países vecinos por recursos presentes en todos los países andinos, lo cual resultaría en una 'guerra de precios' (Vogel, 2007) ${ }^{2}$, la CAN adoptó la Decisión $391^{3}$ que regula el acceso a los recursos genéticos asociados a los conocimientos tradicionales de sus pueblos indígenas, con miras a la protección de los derechos colectivos de este grupo en situación de especial protección en la Subregión. Así como el reconocimiento de los conocimientos tradicionales de los pueblos indígenas de la CAN como parte del desarrollo de conocimientos en ciencia y tecnología, razón por la cual su protección está incorporada en el Régimen Común sobre Propiedad Industrial, Decisión $486^{4}$.

1 Para mayor referencia se sugiere revisar: Anaya Vera, Esther y Vera Penachi, Maritza. El valor nutracéutico de los alimentos andino-nativos domesticados y cultivados por pueblos indígenas de los Países Miembros de la Comunidad Andina y su protección por el Derecho Supranacional. En: Revista de Análisis Especializado de Jurisprudencia - RAE Jurisprudencia. Lima: Thomson Reuters, tomo 51, septiembre 2012.

2 En Ruiz, M. (2008)

3 Comunidad Andina. Decisión 391. Art. 7: «Los Países Miembros, de conformidad con esta Decisión y su legislación nacional complementaria, reconocen y valoran los derechos y la facultad para decidir de las comunidades indígenas, afroamericanas y locales, sobre sus conocimientos, innovaciones y prácticas tradicionales asociados a los recursos genéticos y sus productos derivados".

4 Comunidad Andina. Decisión 486: Art. 3: «Los Países Miembros asegurarán que la protección conferida a los elementos de la propiedad industrial se concederá salvaguardando y respetando su patrimonio biológico y genético, así como los conocimientos tradicionales de sus comunidades indígenas, afroamericanas o locales. En tal virtud, la concesión de patentes que versen sobre invenciones desarrolladas a partir de material obtenido de dicho patrimonio o dichos conocimientos estará supeditada a que ese material haya sido adquirido de conformidad con 
$\mathrm{Al}$ respecto, es preciso destacar que los Países Miembros de la CAN concentran un relevante porcentaje de la diversidad biológica del planeta y por consiguiente el uso, comercialización e industrialización de muchos de sus componentes les proporciona un valor estratégico en el contexto internacional. Lo referido dado que los recursos genéticos tienen un gran valor económico por ser fuente primaria de productos y procesos para la industria mundial5. Asimismo:

El aprovechamiento de los recursos genéticos por la biotecnología ha sido frecuentemente impulsado por los conocimientos tradicionales, de los que se han valido los investigadores para iniciar su trabajo sabiendo qué recursos genéticos tienen aplicaciones prácticas y la forma y finalidad con las que se han venido utilizando (...) se estima, en efecto, que el 40 por 100 de los medicamentos que actualmente se encuentran en fase de prueba son derivados de plantas y que el 75 por 100 de esas plantas de las que proceden eran utilizadas por la llamada medicina tradicional. (Massaguer, 2002).

Cabe hacer hincapié en que la titularidad de los conocimientos tradicionales de quienes han domesticado los alimentos nativos andino-amazónicos durante miles de años, le corresponde exclusivamente a los pueblos indígenas que habitan en los Países Miembros de la CAN (ni a un particular ni al Estado); conforme expresamente lo dispone el Derecho Comunitario Andino y lo implementa adecuadamente uno de sus Países Miembros, Perú, en su ley nacional $27811^{6}$.

Lo sostenido, en cuanto los conocimientos tradicionales de los pueblos indígenas son de propiedad colectiva y están relacionados material y espiritualmente con sus territorios. En este sentido, el respeto al territorio de los pueblos indígenas es fundamental para la continuidad de sus vínculos ancestrales que les proporcionan cohesión social e identidad cultural a este colectivo, según el Congreso de la República del Perú (2008).

Conforme lo ha detallado el Tribunal de Justicia de la CAN en su Interpretación Prejudicial 60-IP-2012, el patrimonio cultural e intelectual de los pueblos indígenas se encuentra conformado por las prácticas, los conocimientos y los modos de vida tradicionales que caracterizan a un pueblo indígena y comprende:

- La lengua, el arte, la música, la danza, la canción y la ceremonia;

- Las prácticas y los conocimientos agrícolas, técnicos y ecológicos;

- La espiritualidad, los sitios sagrados y los restos humanos ancestrales;

- La documentación sobre los elementos precedentes.

el ordenamiento jurídico internacional, comunitario y nacional. Los Países Miembros reconocen el derecho y la facultad para decidir de las comunidades indígenas, afroamericanas o locales, sobre sus conocimientos colectivos».

5 Comunidad Andina. Decisión 391.

6 Los pueblos indígenas del Perú mantienen su cultura y espacios propios desde antes de la existencia del Estado. 
Por consiguiente, se encuentran protegidos los conocimientos tradicionales de los pueblos indígenas, así como las expresiones de su folclore y creatividad tradicionales. De manera complementaria, la Comunidad Andina (2005) señala que los conocimientos tradicionales están relacionados con los siguientes saberes y prácticas:

- Ciencias naturales (e.g. biología, botánica, zoología, taxonomía indígena)

- Lingüística, cantos, rituales, danzas y ritmos

- Curaciones, medicina y farmacología

- Artesanía, cerámica, tejidos y diseños

- Manejo de la biodiversidad, desarrollo sostenible, cultivos asociados, manejo de ecosistemas, manejo forestal y manejo de cuencas hidrográficas

- Conocimiento de uso actual, previo o potencial de especies de plantas y de animales, así como de suelos y minerales, conocido por un grupo cultural

- Conocimiento de preparación, proceso y almacenamiento de especies

- Conocimientos sobre conservación de ecosistemas

- Ceremonias y curaciones realizadas dentro y fuera de su ámbito cultural

- Sistemas de derecho consuetudinario y valores morales

$\mathrm{Al}$ respecto, es preciso destacar que el Tribunal de Justicia de la CAN, conforme lo expresa en su citada Interpretación Prejudicial, considera que los productos artesanales y el procesamiento de especies para hacer alimentos entran dentro del concepto de "conocimientos tradicionales», ya que dicho procesamiento y elaboración de productos cuentan con una determinada carga cultural y arraigo histórico (Comunidad Andina, 2012).

La protección de los conocimientos tradicionales de los pueblos indígenas por el derecho comunitario andino

En cumplimiento de lo dispuesto por el Art. 15.7 del Convenio sobre la Diversidad Biológica - CDB (1992) que obliga a las Partes Contratantes adoptar medidas legislativas, administrativas o de política que garanticen la repartición justa y equitativa de beneficios generados de la utilización de recursos genéticos; el año 1996 la Comunidad Andina (CAN) fue la primera Organización Internacional de integración que aprobó un régimen subregional en materia de acceso a los recursos genéticos y el reparto equitativo de beneficios con la adopción de su Decisión 391 (Comunidad Andina, 2007).

De esta manera, los conocimientos tradicionales de los pueblos indígenas son reconocidos y protegidos en el Derecho Comunitario Andino por las Decisiones 391: «Régimen Común sobre Acceso a los Recursos Genéticos» y 486 «Régimen Común sobre Propiedad Industrial» de la CAN. A través de la primera Decisión se regula el acceso a los recursos genéticos relacionados con conocimientos tradicionales de pueblos indígenas y la segunda reconoce y protege jurídicamente los conocimientos tradicionales de los pueblos indígenas. Ello, puesto que: «Estos conocimientos están estrechamente 
asociados con los recursos genéticos y, en este sentido, siempre que exista asociación entre el conocimiento y los recursos genéticos, el acceso a estos últimos conlleva a definir asimismo condiciones de acceso y uso de los primeros» (Comunidad Andina, 2007).

Por consiguiente, en el marco de la CAN se reconoce el derecho a la protección jurídica de los conocimientos tradicionales asociados a los recursos genéticos; a favor de los pueblos indígenas que los han desarrollado, conservado y transmitido de generación en generación, y la regulación del acceso a estos recursos (Massaguer, 2002).

En el plano internacional, las discusiones sobre el acceso a los recursos genéticos asociados a los conocimientos tradicionales de los pueblos indígenas, el cual podría mover anualmente billones de dólares al estar estrechamente relacionado con la inversión para el desarrollo de la industria mundial, se encuentran en importantes foros como la Organización Mundial de la Propiedad Intelectual (OMPI) y la Organización Mundial del Comercio (OMC), estando aún pendiente el reconocimiento internacional de la titularidad colectiva de los pueblos indígenas sobre sus conocimientos tradicionales asociados a los recursos genéticos, el cual debe partir del presupuesto que «los conocimientos de los pueblos indígenas son de carácter colectivo e intergeneracional y forman parte del territorio, de la cultura y de la cosmovisión de los pueblos indígenas». En este sentido, la OMPI ha manifestado que:

Uno de los tipos de apropiaciones de que a menudo se quejan las comunidades indígenas y tradicionales es la práctica de reivindicar de forma falsa o de manera que induzca a error la autenticidad o el origen. Por ejemplo, un recuerdo turístico barato puede llevar una etiqueta en la que se indique falsamente que es «auténtico», «fabricado por indígenas» u originario de una comunidad en particular (...). A los pueblos indígenas y las comunidades tradicionales les preocupa que empresas comerciales no autorizadas tomen sus vocablos, nombres, diseños, símbolos y otros signos distintivos y los utilicen y registren como marcas.

Al respecto, la Comunidad Andina — a diferencia de la OMPI y la OMC — ha logrado a través de su Derecho Comunitario proteger expresa y ampliamente los conocimientos tradicionales de sus pueblos indígenas, afrodescendientes y locales, cuya normativa se detalla a continuación:

Decisión 391: «Régimen Común sobre Acceso a los Recursos Genéticos» (1996)

Art. 7. Los Países Miembros, de conformidad con esta Decisión y su legislación nacional complementaria, reconocen y valoran los derechos y la facultad para decidir de las comunidades indígenas, afroamericanas y locales, sobre sus conocimientos, innovaciones y prácticas tradicionales asociados a los recursos genéticos y sus productos derivados. 
8va. Disposición Transitoria.- La Junta (hoy Secretaría General de la CAN), elaborará, dentro de un plazo de tres meses posteriores a la presentación de estudios nacionales por los Países Miembros, una propuesta para establecer un régimen especial o una norma de armonización, según corresponda, que esté orientado a fortalecer la protección de los conocimientos, innovaciones y prácticas tradicionales de las comunidades indígenas, afroamericanas y locales, de conformidad con lo establecido en el artículo 7 de la presente Decisión, el Convenio 169 de la OIT y el CDB.

\section{Decisión 486: «Régimen Común sobre Propiedad Industrial» (2000)}

Del Patrimonio Biológico y Genético y de los Conocimientos Tradicionales

Art. 3.- Los Países Miembros asegurarán que la protección conferida a los elementos de la propiedad industrial se concederá salvaguardando y respetando su patrimonio biológico y genético, así como los conocimientos tradicionales de sus comunidades indígenas, afroamericanas o locales. En tal virtud, la concesión de patentes que versen sobre invenciones desarrolladas a partir de material obtenido de dicho patrimonio o dichos conocimientos estará supeditada a que ese material haya sido adquirido de conformidad con el ordenamiento jurídico internacional, comunitario y nacional.

Los Países Miembros reconocen el derecho y la facultad para decidir de las comunidades indígenas, afroamericanas o locales, sobre sus conocimientos colectivos.

Artículo 136. - No podrán registrarse como marcas aquellos signos cuyo uso en el comercio afectara indebidamente un derecho de tercero, en particular cuando:

g) consistan en el nombre de las comunidades indígenas, afroamericanas o locales, o las denominaciones, las palabras, letras, caracteres o signos utilizados para distinguir sus productos, servicios o la forma de procesarlos, o que constituyan la expresión de su cultura o práctica, salvo que la solicitud sea presentada por la propia comunidad o con su consentimiento expreso.

\section{Decisión 523: Estrategia Regional de Biodiversidad para los Países del Trópico} Andino (2002)

\subsection{Conocimientos tradicionales}

Los conocimientos tradicionales referidos a la biodiversidad tienen, como lo reconoce la Decisión 391 de la CAN, «importancia estratégica internacional», debido a que constituyen la llave para acceder más fácilmente al aprovechamiento de los recursos de la diversidad biológica; y porque son la base para facilitar y hacer más expedita la identificación científica de los atributos que poseen los recursos genéticos y, en general, los biológicos. Más aún, a lo largo de la historia, incluido el presente, los conocimientos tradicionales han sido la base que sustenta las prácticas de aprovechamiento sostenible de la biodiversidad, aplicadas por sociedades con estilos tradicionales de vida pertinentes para la conservación y uso sostenible de la diversidad biológica. Cabe destacar que 
entre los conocimientos y las prácticas tradicionales, existen relaciones indisolubles, pues los primeros nacen, se recrean e innovan a partir de las prácticas cotidianas de aprovechamiento de la biodiversidad (y en especial de los sistemas de producción), lo que determina también que ambos, conocimientos y prácticas tradicionales, sean inseparables del hábitat tradicional en que se desarrollan y recrean; y, más ampliamente, de la cultura y forma de vida de las colectividades a las que pertenecen (...).

e) Un tema central que debe ser definido es el alcance y los mecanismos de participación representativa y consulta previa de los pueblos indígenas, comunidades locales y afroamericanas en la definición e implementación de una estrategia de protección y recuperación de sus conocimientos y prácticas tradicionales referidos a la biodiversidad.

Carta Andina para la Promoción de los Derechos Humanos (2002)

Art. 38. Reconocen, igualmente, que los pueblos indígenas y comunidades de afrodescendientes, dentro del marco de las legislaciones nacionales y de la normativa sobre derechos humanos, tienen derecho a mantener y desarrollar sus identidades y costumbres en lo cultural, espiritual, político, económico y jurídico; a la propiedad y posesión de las tierras o territorios que tradicionalmente ocupan; a no ser desplazados de ellos y a retornar en caso de serlo; a conservar sus propias formas de organización social, ejercicio de la autoridad y administración de justicia; a desarrollar y mantener su patrimonio cultural tangible e intangible; y a la protección de sus conocimientos ancestrales colectivos y al ejercicio de sus prácticas tradicionales.

Por consiguiente, la Comunidad Andina protege supranacionalmente los conocimientos tradicionales de sus pueblos indígenas.

\section{El Tribunal de Justicia de la Comunidad Andina y la protección de los conocimientos tradicionales de los pueblos indígenas con enfoque de Derechos Humanos}

El Tribunal de Justicia de la Comunidad Andina a través de su Interpretación Prejudicial 60-IP-2012 de octubre de 2012, se pronunció con relación a la protección de los conocimientos tradicionales de los pueblos indígenas en la Comunidad Andina, en conformidad con el Derecho Internacional de los Derechos Humanos. Lo referido, a partir de una solicitud de interpretación prejudicial presentada por la Corte Constitucional de la República de Colombia relativa a la aplicación de las Decisiones 391 y 486 de la CAN en el registro de las marcas Coca Indigena y Coca Zagradha, a favor de un tercero ajeno a un pueblo indígena. 
La solicitud de interpretación prejudicial al Tribunal de Justicia de la CAN se originó en el marco de la tutela demandada por la Organización Nacional Indígena de Colombia (ONIC) contra la Superintendencia de Industria y Comercio (SIC). Lo referido, al haber concedido la SIC a un particular ajeno a los pueblos indígenas, el registro de la marca Coca Indigena para distinguir servicios de «comercialización, publicidad, distribución y venta a terceros de productos artesanales y legales a base de hoja de coca y con aplicaciones en los campos homeopático y alimenticio».

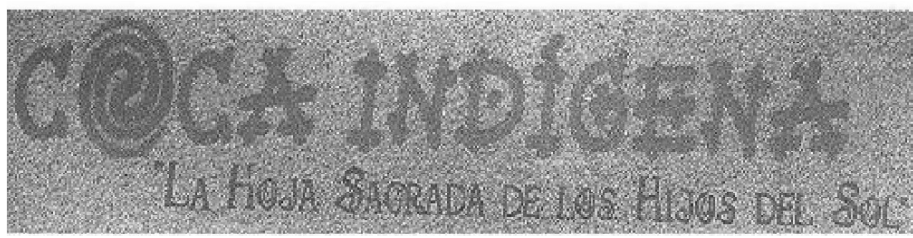

Así como también el registro de la marca Coca Zagradha para distinguir «aromáticas e infusiones, productos de pastelería y repostería a base de coca indígena legalmente cultivada, mambe (hoja selecta de coca tostada)».

Es a partir de lo referido que la demandante, la Organización Nacional Indígena de Colombia, formuló una demanda de tutela contra la Superintendencia de Industria y Comercio, por la posible vulneración de los derechos fundamentales de los pueblos indígenas a «la consulta previa e informada; a la propiedad colectiva; a la autonomía; a la participación en la vida social y económica de la Nación; a la identidad e integridad étnica y cultural; a la autonomía de los pueblos indígenas; a la protección de la riqueza cultural de la Nación; al debido proceso y al ambiente sano de los pueblos indígenas de Colombia».

En opinión de la ONIC, el registro de las referidas marcas habrían vulnerado el Derecho Comunitario Andino, en particular la normativa relativa a la protección de los conocimientos tradicionales de los pueblos indígenas dispuesta en las Decisiones andinas 391 y 486; al originar una explotación no consentida de la identidad cultural de los pueblos indígenas por un particular no autorizado para usufructuar sus símbolos e identidad, con el propósito de incrementar las ventas de sus productos elaborados a base de hoja de coca.

Lo referido, no obstante, la Superintendencia de Industria y Comercio de la República de Colombia reconociera oportunamente que la hoja de coca pertenece a los pueblos indígenas, afirmando en una de sus respuestas que:

Está suficientemente documentado que la hoja de coca es tanto patrimonio biológico, como representa un valor cultural de sin igual importancia de los pueblos indígenas y en consecuencia se convierte en patrimonio cultural de la Nación, atendiendo prin- 
cipios constitucionales, en particular 7 y 8 de nuestra Carta Fundamental. Por otra parte el artículo 7 de la Decisión 391, Régimen Común sobre Acceso a los Recursos Genéticos, reconoce la facultad de decidir de manera autónoma el uso de tales recursos y sobre las innovaciones que se hagan de los mismos. Pero entendemos que en función de la autonomía que el estado colombiano les reconoce, corresponde a ustedes definir quién y de qué manera usa ese patrimonio, pues mal puede nuestra entidad invadir competencias que no son suyas definiendo una situación que la ley resolvió (Comunidad Andina, 2012).

Asimismo, la ONIC alegó que en el registro de la marca Coca Indígena se reemplaza la letra 'O' por un espiral que alude al símbolo heráldico de varios pueblos indígenas como los tule, ijku, nasa, misak y otras culturas.

En el contexto referido, la Corte Constitucional de Colombia solicitó interpretación prejudicial al Tribunal de Justicia de la CAN en lo relativo a la aplicación de la normativa comunitaria andina; al disponer el Art. 32 del Tratado de Creación del Tribunal de Justicia de la Comunidad Andina que: "Corresponderá al Tribunal interpretar por vía prejudicial las normas que conforman el ordenamiento jurídico de la Comunidad Andina, con el fin de asegurar su aplicación uniforme en el territorio de los Países Miembros». En este sentido, la interpretación prejudicial se constituye en un sistema de colaboración entre el juez nacional y el comunitario (Comunidad Andina, 2011), tal como lo ha sostenido el Tribunal de Justicia de la CAN en el proceso 142-IP-2003, al afirmar que:

Esta relación de colaboración se realiza con la finalidad de interpretar la norma comunitaria desde el punto de vista jurídico y que consiste en explicar el significado de la norma para poder determinar su alcance y sentido jurídico; tiene como propósito, mantener la unidad de criterio sobre la legislación comunitaria en los Países Andinos, evitando que se produzcan tantas y diferentes interpretaciones que impidan la aplicación uniforme de la Norma Jurídica Andina.

La solicitud de interpretación prejudicial por parte del juez nacional puede ser facultativa u obligatoria, teniendo ambas figuras jurídicas las siguientes características, conforme expresamente lo ha detallado el Tribunal de Justicia de la CAN en su Interpretación Prejudicial del Proceso 57-IP-2012: 


\begin{tabular}{|c|c|}
\hline $\begin{array}{l}\text { INTERPRETACIÓN PREJUDICIAL } \\
\text { FACULTATIVA }\end{array}$ & $\begin{array}{l}\text { INTERPRETACIÓN PREJUDICIAL } \\
\text { OBLIGATORIA }\end{array}$ \\
\hline $\begin{array}{l}\text { Solicitud facultativa: El juez de instancia no está } \\
\text { obligado a solicitarla. }\end{array}$ & $\begin{array}{l}\text { Solicitud obligatoria: El juez de única o } \\
\text { última instancia ordinaria está obligado a } \\
\text { solicitarla. }\end{array}$ \\
\hline $\begin{array}{l}\text { Su aplicación es obligatoria: si bien el juez de } \\
\text { instancia no está obligado a solicitarla, una vez } \\
\text { requerida y expedida sí tiene el deber de acatarla al } \\
\text { resolver el caso concreto. }\end{array}$ & $\begin{array}{l}\text { Su aplicación es obligatoria: Una vez } \\
\text { expedida la interpretación prejudicial debe } \\
\text { ser acatada para resolver el caso concreto. }\end{array}$ \\
\hline $\begin{array}{l}\text { Es una herramienta directa: el juez de instancia puede } \\
\text { acudir directamente ante el Tribunal sin necesidad } \\
\text { de tramitar la solicitud mediante otra autoridad o } \\
\text { instancia. No es necesario que se haga por medio } \\
\text { de un exhorto o cualquier otra forma para recaudar } \\
\text { información en el exterior; se puede requerir con un } \\
\text { simple oficio dirigido al TJCAN. }\end{array}$ & $\begin{array}{l}\text { Es una herramienta directa: el juez de } \\
\text { última instancia ordinaria puede acudir } \\
\text { directamente al Tribunal sin necesidad de } \\
\text { tramitar la solicitud mediante otra autoridad } \\
\text { o instancia. No es necesario que se haga por } \\
\text { medio de un exhorto o cualquier otra forma } \\
\text { para recaudar información en el exterior; se } \\
\text { puede requerir con un simple oficio dirigido } \\
\text { al TJCAN. }\end{array}$ \\
\hline $\begin{array}{l}\text { No es una prueba. En el proceso no tiene carácter } \\
\text { probatorio. Su naturaleza es de un incidente } \\
\text { procesal, pero en el caso de solicitud facultativa } \\
\text { no suspende el proceso. La nota informativa sobre } \\
\text { el planteamiento de la solicitud de interpretación } \\
\text { prejudicial por los Órganos Judiciales Nacionales, en } \\
\text { el punto } 5 \text { establece lo siguiente: «La interpretación } \\
\text { prejudicial no es ni puede asimilarse a una prueba, } \\
\text { tampoco es la simple absolución de un cuestionario, } \\
\text { ni está llamada a constituirse en un informe de } \\
\text { expertos o en una opinión jurídica de tipo doctrinal. } \\
\text { Su naturaleza es la de un incidente procesal, de } \\
\text { carácter no contencioso». }\end{array}$ & $\begin{array}{l}\text { No es una prueba. En el proceso no tiene } \\
\text { carácter probatorio. Su naturaleza es de un } \\
\text { incidente procesal. Suspende el proceso. }\end{array}$ \\
\hline $\begin{array}{l}\text { Se puede solicitar en cualquier momento antes de } \\
\text { emitir sentencia, pero su solicitud «no» suspende } \\
\text { el proceso. Si llegare el momento de dictar } \\
\text { sentencia y no se hubiere recibido la interpretación } \\
\text { prejudicial, el juez nacional debe resolver el asunto. } \\
\text { De conformidad con lo anterior, es recomendable } \\
\text { que el juez solicite la interpretación prejudicial en } \\
\text { un momento procesal relativamente alejado de la } \\
\text { sentencia. }\end{array}$ & $\begin{array}{l}\text { Se puede solicitar en cualquier momento } \\
\text { antes de emitir sentencia y su solicitud } \\
\text { suspende el proceso. Hasta que el juez } \\
\text { nacional no reciba la interpretación } \\
\text { prejudicial el proceso debe quedar } \\
\text { suspendido. Aunque la interpretación } \\
\text { prejudicial se puede solicitar en cualquier } \\
\text { momento, es recomendable que se haga } \\
\text { cuando el juez tenga todos los elementos } \\
\text { de juicio para resumir el marco fáctico y } \\
\text { jurídico del litigio, así como para realizar } \\
\text { algunas preguntas de carácter interpretativo } \\
\text { al Tribunal de Justicia de la Comunidad } \\
\text { Andina. }\end{array}$ \\
\hline
\end{tabular}

Fuente: Tribunal de Justicia de la Comunidad Andina. Interpretación Prejudicial 60-IP-2012. 
Al respecto, el Tribunal de Justicia de la CAN, mediante su interpretación prejudicial 60-IP-2012, destacó los siguientes efectos que se derivan del incumplimiento de los jueces nacionales a su obligación de solicitar interpretación prejudicial:

- La sentencia dictada adolecería de nulidad, dado que a partir de los principios generales de aplicación inmediata y el efecto directo de la normativa comunitaria andina, la interpretación prejudicial obligatoria forma parte de la normativa procesal nacional de manera inmediata y automática. Por consiguiente, cualquiera de las partes de un litigio en donde el juez de única o última instancia no hubiera solicitado la interpretación prejudicial, podrá alegar la nulidad o invalidez de la sentencia de conformidad con las vías procesales internas disponibles: recursos extraordinarios de revisión, casación, etc ${ }^{7}$.

- La sentencia dictada estaría violando el derecho fundamental al debido proceso, al constituir la interpretación prejudicial obligatoria una norma procesal. En este sentido, si la normativa interna lo permite, cualquiera de las partes podría entablar acciones constitucionales como la tutela, el amparo, la acción de protección, etc.

- La falta de solicitud de interpretación prejudicial obligatoria por parte del juez nacional, constituye un incumplimiento del Derecho Comunitario Andino por parte del País Miembro; siendo susceptible de la interposición de una acción de incumplimiento promovida por la Secretaría General, cualquier País Miembro o cualquier persona afectada en sus derechos (Comunidad Andina, 2010).

- Las o los afectados por este incumplimiento podrían solicitar la reparación del daño causado, utilizando las figuras procesales nacionales. Para tal efecto, la sentencia de incumplimiento constituye título legal y suficiente para que el particular pueda solicitar al juez nacional la indemnización de daños y perjuicios que corresponda.

7 Ricardo Vigil Toledo: Reflexiones en torno a la construcción de la Comunidad Sudamericana de Naciones. Quito, octubre 2006. Págs. 26-29. Así, por ejemplo en la Sentencia de Casación de la Corte Suprema del Ecuador, Expediente 256-2001 del 31 de Agosto de 2001, declararon la nulidad de la sentencia y repusieron la causa al estado en que se debió dar cumplimiento a la solicitud de interpretación al Tribunal Andino por cuanto el asunto versaba sobre la aplicación de las normas contenidas en los artículo 81, 83 lit. a) y 102 de la Decisión 344 de la Comisión del Acuerdo de Cartagena. En otro caso, en la Sentencia de la Corte Suprema del Ecuador, Tercera Sala de lo Civil y Mercantil del 5 de Octubre de 1999, claramente estableció en sus considerandos que era obligación de la Corte Superior de Guayaquil, por ser la última instancia de grado, de solicitar la consulta al Tribunal de justicia de la Comunidad Andina, y que dicha obligación no se extendía a los Recursos de casación por ser éstos extraordinarios a diferencia de los ordinarios y, en tal situación son las Cortes que absuelven el grado en última instancia los obligados a formular la consulta. En el caso de Espańa, mediante sentencia STC 58/2004 del Tribunal Constitucional, se ha declarado fundado un Recurso de Amparo por incumplimiento de la obligación. El Tribunal al anular la sentencia del Tribunal Supremo de Justicia de Cataluña ha actuado, lo mismo que los jueces del Tribunal Supremo de Ecuador, como verdaderos jueces comunitarios al restablecer las reglas del debido proceso y aplicar el Derecho comunitario en los casos en que la consulta a los Tribunales de Justicia de las respectivas Comunidades es obligatoria. 
Asimismo, todo juez nacional que solicite una interpretación prejudicial, está obligado a enviar al Tribunal de Justicia de la CAN una copia de la sentencia dictada en el proceso interno, a efectos que pueda realizarse el control comunitario correspondiente.

A partir de lo referido, el Tribunal de Justicia de la CAN interpretó el artículo 136 literal g) de la Decisión 486 de la CAN que "prohíbe» el registro de marcas cuando «consistan en el nombre de las comunidades indígenas, afroamericanas o locales, o las denominaciones, las palabras, letras, caracteres o signos utilizados para distinguir sus productos, servicios o la forma de procesarlos, o que constituyan la expresión de su cultura o práctica, salvo que la solicitud sea presentada por la propia comunidad o con su consentimiento expreso».

En este sentido, el TJCAN interpretó que la norma comunitaria andina contempla como única excepción para que un tercero ajeno a un pueblo indígena pueda registrar una marca relacionada con sus conocimientos tradicionales: el consentimiento expreso del pueblo indígena. Por consiguiente, dispuso que los Países Miembros de la CAN, al aplicar el artículo 136 literal g) de la Decisión andina 486: «deberán procurar que el consentimiento expreso al que alude la mencionada disposición sea obtenido en el marco del respeto a los derechos fundamentales de los pueblos indígenas y, en consecuencia, mediante 'la vía idónea para ello', consultando, claro está, el escenario local, interamericano ${ }^{8}$ y universal de protección de los derechos de los pueblos indígenas»".

En este sentido, en aplicación del principio del complemento indispensable en lo no regulado por el Derecho Comunitario Andino, el TJCAN se remite al sistema nacional, interamericano y universal de protección de los derechos humanos de los pueblos indígenas para que el juez nacional defina la 'vía idónea' a través de la cual los pueblos indígenas expresen su consentimiento en conformidad con el respeto de sus derechos fundamentales. Lo sostenido porque:

La normativa comunitaria de propiedad industrial debe estar en concordancia y armonía con la protección de los derechos humanos, ya que éstos son el soporte de actuación de todos los operadores jurídicos subregionales. No se podría entender la norma comunitaria andina de propiedad intelectual de manera alejada de dicho amparo, máxime si la célula fundamental del proceso de integración es el propio habitante de la subregión (párrafo 3 del artículo 1 del Acuerdo de Cartagena).

En este sentido, el TJCAN agrega que «Sobre este fundamento se expidió el artículo 3 de la Decisión 486 de la Comisión de la Comunidad Andina, cuya finalidad es lograr

8 Dentro de las múltiples sentencias de la Corte Interamericana sobre el tema, conviene resaltar la sentencia "Caso Pueblo Indigena Kichwa de Sarayaku vs. Ecuador». Fondo y reparaciones. Sentencia de 27 de junio de 2012, Serie C, No 245.

9 TJCAN. Interpretación Prejudicial. Proceso 60-IP-2012. Sexta cláusula. 
ponderar los derechos de propiedad industrial con los derechos de los pueblos y comunidades indígenas» ${ }^{10}$; Art. 3 que dispone lo siguiente: «Los Países Miembros asegurarán que la protección conferida a los elementos de la propiedad industrial se concederá salvaguardando y respetando su patrimonio biológico y genético, así como los conocimientos tradicionales de sus comunidades indígenas, afroamericanas o locales».

De esta manera, el TJCAN, mediante su Interpretación Prejudicial 60-IP-2012, reitera que «dentro de los principios generales del Derecho comunitario andino se encuentra el respeto y la protección de los derechos humanos, esto en concordancia con las tradiciones constitucionales comunes de los Países Miembros. Situación que no debe ser desatendida por ningún operador jurídico comunitario» ${ }^{11}$.

Asimismo, el TJCAN agregó que en el Derecho Comunitario Andino ya existen normas que prevén la consulta previa a los pueblos indígenas en conformidad con el Derecho Internacional de los Derechos Humanos, como lo es la contenida en el punto 2.3, literal e) del anexo de la Decisión 523: «Estrategia Regional de Biodiversidad para los Países del Trópico Andino», al disponer que:

Un tema central que debe ser definido es el alcance y los mecanismos de participación representativa y consulta previa de los pueblos indígenas, comunidades locales y afroamericanas en la definición e implementación de una estrategia de protección y recuperación de sus conocimientos y prácticas tradicionales referidos a la biodiversidad.

A partir de lo desarrollado, el TJCAN, en la Interpretación Prejudicial analizada, dispuso que el Juez Consultante determine si los símbolos contenidos en las marcas Coca Indigena y Coca Zagradha constituyen 'caracteres o signos de las comunidades indígenas utilizados para distinguir sus productos', o son la expresión de su cultura o práctica y, en consecuencia, si fue otorgado el consentimiento expreso mediante el mecanismo de consulta previa, en conformidad con la protección de los derechos humanos de los pueblos indígenas en los ordenamientos jurídicos nacionales de sus Países Miembros y el Derecho Internacional de los Derechos Humanos ${ }^{12}$.

\section{Conclusión}

A partir del análisis de la jurisprudencia del Tribunal de Justicia de la Comunidad Andina se concluye que la protección de los conocimientos tradicionales de los pueblos indígenas de la CAN se realiza con enfoque de derechos humanos porque uno de los

10 TJCAN. Op. Cit.

11 Ibíd.

12 Ibíd. Sexta Conclusión. 
Principios Generales del Derecho Comunitario Andino es el respeto y la protección de los derechos humanos (máxime si la célula fundamental del proceso de integración es el propio habitante de la subregión'(párrafo 3 del Art. 1 del Acuerdo de Cartagena). Y, en consecuencia, la normativa comunitaria de propiedad industrial debe estar en concordancia y armonía con la protección de los derechos humanos, fundamento sobre el cual se expidió el Art. 3 de la Decisión CAN 486: Régimen Común sobre Propiedad Industrial, cuya finalidad es lograr ponderar los derechos de propiedad industrial con los derechos de los pueblos indígenas (Procesos TJCAN 60-IP-2012 y 284-IP-2014).

De esta manera, los conocimientos tradicionales de los pueblos indígenas al ser expresión de su derecho fundamental a la identidad cultural, el mecanismo que debe ser utilizado para garantizar su consentimiento expreso, es la consulta previa; en conformidad con lo regulado por el Derecho Internacional de los Derechos Humanos y el Derecho Constitucional de sus Países Miembros.

\section{Referencias bibliográficas}

Anaya, E. y Vera, M. (2012). El valor nutracéutico de los alimentos andino-nativos domesticados y cultivados por pueblos indígenas de los Países Miembros de la Comunidad Andina y su protección por el Derecho Supranacional. En: Revista de Análisis Especializado de Jurisprudencia-RAE Jurisprudencia. Lima: Thomson Reuters (51).

Comunidad Andina. (2005). Elementos para la protección sui generis de los conocimientos tradicionales colectivos e integrales desde la perspectiva indígena. Caracas: Secretaría General de la Comunidad Andina y Corporación Andina de Fomento, 2005. Recuperado de http:// www.comunidadandina.org/Upload/201164175851libro_perspectiva_indigena.pdf.

Comunidad Andina. (2006). Lineamientos Técnicos. Apoyo a la negociación internacional de los Paises Miembros de la Comunidad Andina en materia de acceso a recursos genéticos y conocimientos tradicionales. Lima: Secretaría General de la Comunidad Andina y Corporación Andina de Fomento.

Congreso de la República del Perú. (2008). Comisión multipartidaria encargada de estudiar y recomendar la solución a la problemática de los pueblos indigenas. Periodo Legislativo 20082009. Informe sobre los Decretos Legislativos vinculados a los Pueblos Indígenas promulgados por el Poder Ejecutivo en mérito a la Ley N²9157.

Organización Mundial de la Propiedad Intelectual. (1998). Mesa Redonda sobre propiedad intelectual y pueblos indigenas. Ginebra.

Organización Mundial de la Propiedad Intelectual. Propiedad intelectual y expresiones culturales tradicionales o del folklore. Folleto. No1. Recuperado de www.wipo.int/freepublications/es/ tk/913/wipo_pub_913.pdf. 
Organización Mundial de la Propiedad Intelectual. La OMPI y los pueblos indígenas. Folleto N.o 12. Recuperado de www.ohchr.org/Documents/Publications/GuideIPleaflet12sp. pdf.

Massaguer, J. (2002). Algunos aspectos de la protección jurídica de los conocimientos tradicionales asociados a recursos genéticos mediante el sistema de propiedad intelectual. En: Actas de derecho industrial y derecho de autor. (23)

Ruiz, M. (2008). Una lectura crítica de la Decisión 391 de la Comunidad Andina y su puesta en práctica en relación con el Tratado Internacional. En: Recursos Naturales y Ambiente. 53:136-147. San José de Costa Rica: Centro Agronómico Tropical de Investigación y Enseñanza - CATIE.

\section{Jurisprudencia}

Comunidad Andina (2009). Tribunal de Justicia. Interpretación Prejudicial. Proceso 106-IP-2009. Comunidad Andina (2010). Tribunal de Justicia. Interpretación Prejudicial. Proceso 01-IP-2010 Comunidad Andina (2011). Tribunal de Justicia. Interpretación Prejudicial. Proceso 149-IP-2011 Comunidad Andina (2012). Tribunal de Justicia. Interpretación Prejudicial. Proceso 57-IP-2012. Comunidad Andina (2012). Tribunal de Justicia. Interpretación Prejudicial. Proceso 60-IP-2012. Comunidad Andina (2014). Tribunal de Justicia. Interpretación Prejudicial. Proceso 284-IP-2014. 